\title{
CARPENTIER-EDWARDS PERICARDIAL VALVES IN THE MITRAL POSITION: TEN-YEAR FOLLOW-UP
}

\author{
M. R. Aupart, MD \\ P. H. Neville, MD \\ S. Hammami, MD \\ A. L. Sirinelli, MD \\ Y. A. Meurisse, MD \\ M. A. Marchand, MD
}

\begin{abstract}
Objective: The first generation of pericardial valves was withdrawn from the market because of a high rate of premature failure. With an original design, Carpentier-Edwards pericardial valves promised improved results. Methods: One hundred fifty patients who underwent isolated mitral valve replacement, between July 1984 and December 1993, with CarpentierEdwards pericardial bioprostheses in our institution were followed up. Patient mean age was $62.9 \pm 11.9$ years. Operative mortality was $3.3 \%$. All but three patients were followed up for an average of 4.7 years after operation, and total follow-up was $\mathbf{7 1 0}$ patient-years. Results: At the time this article was written, over $80 \%$ of patients were in New York Heart Association class I or II. After 10 years, actuarial survival rate was $71 \%$ (confidence limit $61 \%$ to $81 \%$ ). Valve-related complications included the following: six valve-related deaths $(0.8 \%$ patient-year $)$, five thromboembolic episodes ( $0.7 \%$ patient-year), three cases of endocarditis $(0.4 \%$ patientyear), four reoperations ( $0.5 \%$ patient-year), and four structural valve failures with calcification and stenosis $(0.5 \%$ patient-year). After 10 years, freedom from valve-related complications was $66 \%$ (confidence limit $46 \%$ to $86 \%$ ), from valve-related death $94 \%$ (confidence limit $89 \%$ to $99 \%$ ), from reoperation $90 \%$ (confidence limit $82 \%$ to $98 \%$ ), and from valve failure $76 \%$ (confidence limit $62 \%$ to $90 \%$ ). Conclusions: With a low rate of valve-related events at 10 years and a low rate of structural deterioration with no leaflet tear, this prosthesis is a reliable choice for patients over 60 years of age. (J Thorac Cardiovasc Surg 1997;113:492-8)
\end{abstract}

$\mathrm{T}$ he first generation of pericardial valve has been abandoned by physicians for poor clinical results and a high rate of deterioration characterized by leaflet tear. With an original design, the CarpentierEdwards pericardial bioprosthesis promised improved results. The intermediate follow-up showed a low rate of valve-related events and especially a low rate of deterioration with no leaflet tear, ${ }^{1,2}$ even in the mitral position. ${ }^{3}$ This study reports our experience over 10 years with 150 Carpentier-Edwards pericardial mitral valves (model 6900; Baxter Healthcare Corp., Santa Ana, Calif.) in 149 patients.

From the Department of Cardiac Surgery, Trousseau University Hospital, Tours, France.

Received for publication March 19, 1996; revisions requested April 22, 1996; revisions received Nov. 4, 1996; accepted for publication Nov. 8, 1996.

Address for reprints: M. Aupart, MD, Unité de Chirurgie Cardiaque, Hopital Trousseau, 37044 Tours cedex, France.

Copyright (c) 1997 by Mosby-Year Book, Inc.

$0022-5223 / 97 \$ 5.00+0 \quad \mathbf{1 2 / 1 / 7 9 1 8 2}$

\section{Material and methods}

\section{Patients}

From July 1984 to December 1993, 150 CarpentierEdwards pericardial bioprostheses were used in 149 consecutive patients for isolated mitral valve replacement in our hospital. Patients undergoing multiple valve replacement were excluded from this study, but there were no exclusion for other concomitant operations. There were 71 men (47.3\%) and 79 women (52.7\%). Age ranged from 22 to 82 years with a mean of $62.9 \pm 11.9$ years; 46 patients were younger than 60 years old.

Fifty-nine associated procedures included aortocoronary bypass in 13 patients, tricuspid annuloplasty in 28 , and left atrium plication in 18 .

The main indications for valve replacement were rheumatic fever in 55, dystrophic insufficiency in 41, prosthetic valve dysfunction in 15 , failure of mitral valvuloplasty or commissurotomy in 13 , endocarditis in 13 , ischemic insufficiency in 11, and valve thrombosis in 2 . Clinical presentation was mitral stenosis in 38 patients, mitral insufficiency in 91, and mixed disease in 21. Mean New York Heart Association (NYHA) clinical status was 2.7. Nineteen percent of patients had a chronic atrial fibrillation. The preoperative status is summarized in Fig. 1.

The patients underwent operation through a median 


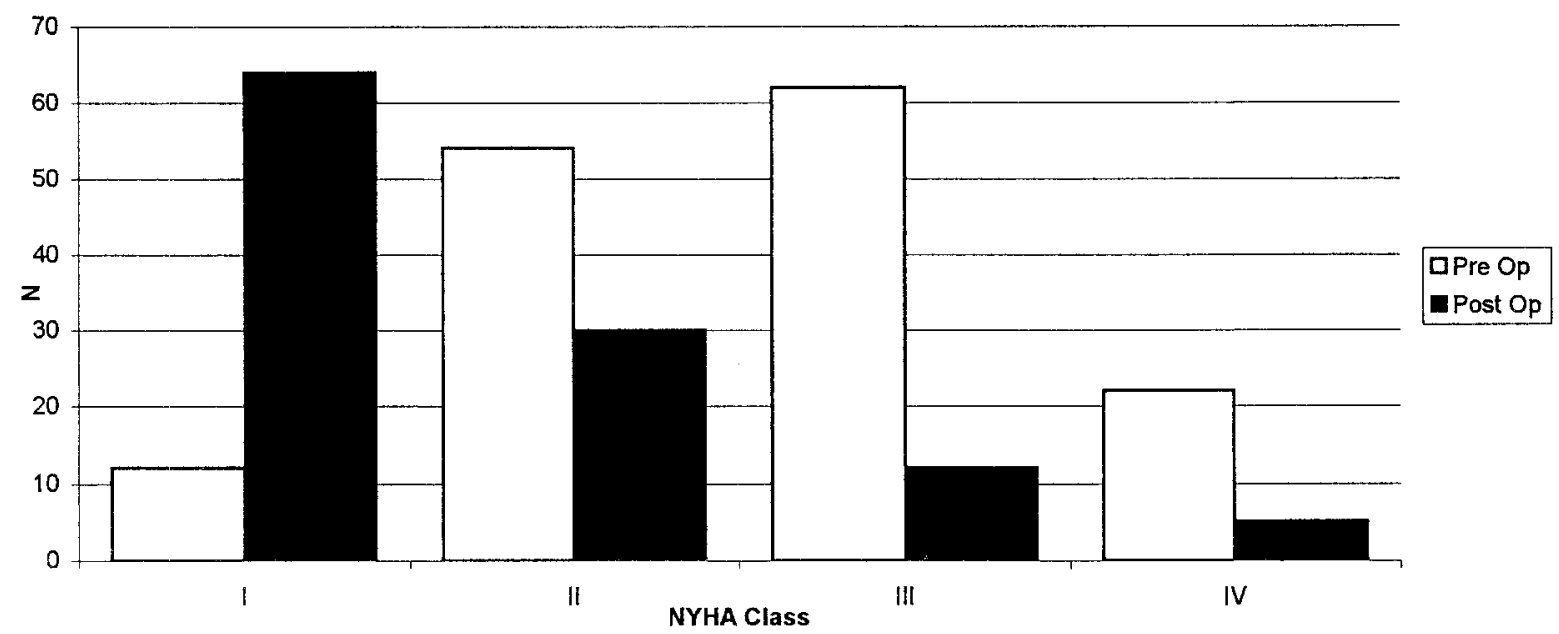

Fig. 1. Clinical status.

sternotomy with standard cardiopulmonary bypass, hemodilution, and general body hypothermia. Myocardial protection was obtained with crystalloid or blood cardioplegic solution and topical cooling. A transseptal approach was used in patients with a small left atrium and in cases of mitrotricuspid surgery. We preserved the posterior leaflet apparatus in every case, and since 1992 we have been trying to preserve the anterior leaflets apparatus. We implanted 49,66,32, and 3 prostheses in 27, 29, 30 , and $33 \mathrm{~mm}$ sizes, respectively.

Postoperative anticoagulant protocol included heparin for 2 days, followed by 1 month of calcium heparin (activated partial thromboplastin time $>1.5 \mathrm{~N}$ ) or acenocoumarol (international normalized ratio 1.5:2) (Giba, Geigy, France). After 1 month, the anticoagulation treatment was discontinued except in patients in atrial fibrillation; the treatment was sometimes modified according to the cardiologist's decision.

Patients were followed up every other year at the same date and with the same procedure. The 10-year follow-up information was obtained during a 3-month interval through questionnaire and telephone contact with cardiologist, family physician, and patient. All but three patients were followed up for an average of 4.7 years after their operation, and total follow-up was 710 patient-years ( $2 \%$ lost to follow-up).

More than $95 \%$ of patients underwent an echocardiographic study at the time of follow-up; among them 30 patients underwent echocardiographic Doppler studies at our institution. They were performed by the same physician with the same procedure.

All data were entered in an IBM computer and analyzed with Sedistat software (Sedia SA, Paris, France). Standard actuarial and linearized statistical techniques were used to describe survival and incidence of valverelated complications. Only the first event for each patient during the study was considered in the actuarial analysis, whereas all events for each patient were considered in linearized rates. Continuous data are presented as mean \pm standard deviation, and actuarial probability and linearized rates are presented as mean and 95\% confidence limits (CL) of the mean. The time interval used for actuarial analysis is in years. Linearized rates are numbers of events per person-year of follow-up.

The guidelines for reporting mortality and morbidity after cardiac valvular operation have been observed in the preparation of this article. ${ }^{4}$

\section{Results \\ Patient survival}

Five patients died within 30 days of the operative period, for a mortality of $3.3 \%$. The major cause of early death was cardiac failure in three patients. One patient died of pulmonary embolism, and another patient died of left ventricular rupture. There were no deaths for patients in NYHA class I or II.

There were 27 late deaths. The cause of death was cardiac-related in six patients $(22 \%)$, valve-related in six $(22 \%)$, and noncardiac in $15(56 \%)$. The actuarial survival rate including operative mortality was $71 \%$ (CL $61 \%$ to $81 \%$ ) after 10 years (Fig. 2).

At the time this article was written, over $80 \%$ of the 117 patients followed up were in NYHA class I or II (Fig. 1), with 56 receiving anticoagulation treatment. Of these, 32 were in atrial fibrillation, 16 had a pacemaker, and eight were in sinus rhythm. Good quality of life (no noise and no anticoagulation) was especially noted in younger patients.

Valve-related complications. Six patients died of valve-related causes (two of endocarditis, one of thromboembolic complication, one of anticoagulant-related hemorrhage, and two of sudden death). The actuarial rate of freedom from valve-related death was $94 \%$ (CL $89 \%$ to $99 \%$ ) at 10 years. No 


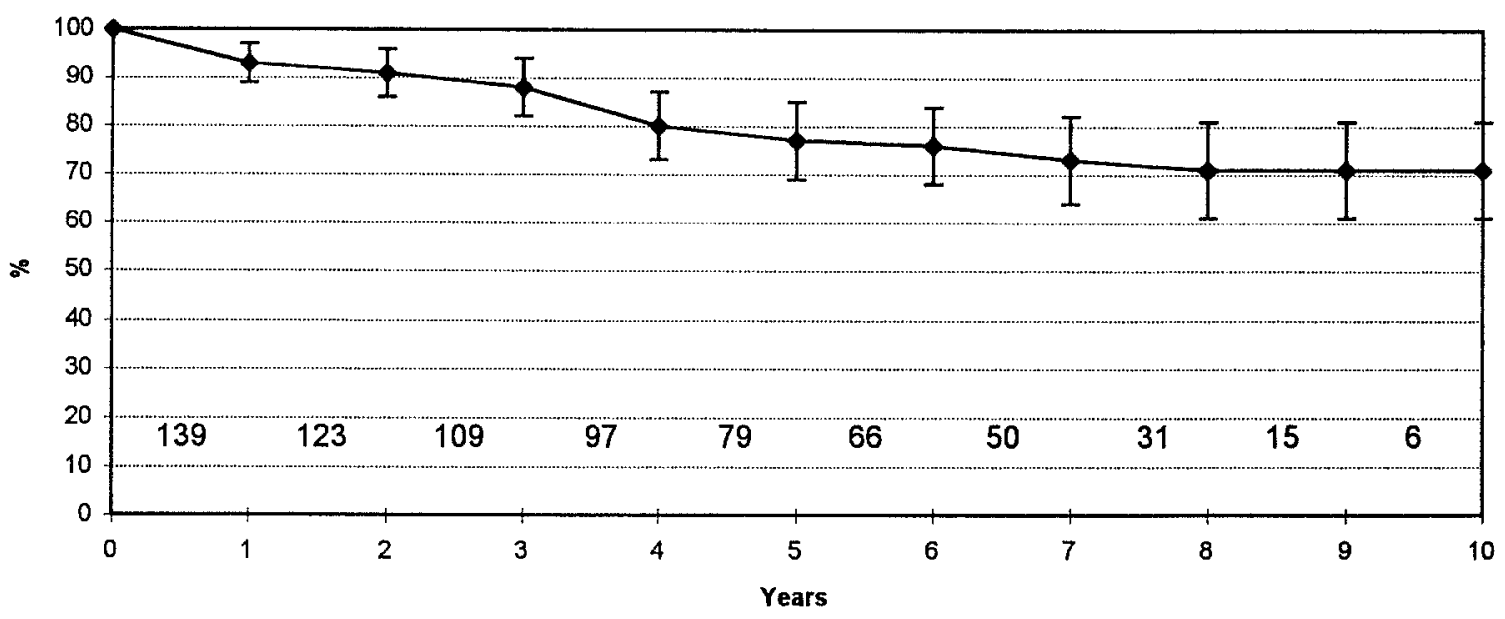

Fig. 2. Patients' actuarial survival.

postmortem examination was available for the sudden death.

Thromboembolism. Five patients had a thromboembolic accident for an actuarial rate of $95 \%$ (CL $90 \%$ to $100 \%$ ) of patients free of thromboembolism at 10 years. The five events were neurologic: one death, one permanent neurologic deficit, and three without sequelae. Three patients were in sinus rhythm, two were in atrial fibrillation, and two had anticoagulation treatment (one in sinus rhythm, one in atrial fibrillation). Linearized rate was $0.7 \%$ patient-years. No thrombosis of the bioprosthesis was observed.

Anticoagulant-related hemorrhage. There were nine cases of hemorrhagic complications meeting the definition of the guidelines, with one death. Of these, three were in sinus rhythm and had no indication for anticoagulation. Linearized rate was $1.2 \%$ patient-year, and 10 -year freedom from anticoagulant hemorrhage was $84 \%$ (CL $70 \%$ to $98 \%$ ).

Endocarditis was reported in three patients, with one in the first 3 months and two in the first year. Two patients died without reoperation, but the diagnosis was not made in our institution, and one had successful medical treatment without recurrence. The linearized rate of endocarditis was $0.4 \%$ patient-years with an actuarial rate of $97 \%$ (CL 94\% to $100 \%$ ) of patients being free of endocarditis at 10 years. No hemolysis was noted in the patients who were followed up.

Four patients required reoperation for an actuarial rate of $90 \%$ (CL $82 \%$ to $98 \%$ ) of patients free of reoperation at 10 years and a linearized rate of $0.5 \%$ patient-years. Causes of reoperation were perivalvular leak in one and structural failure in three. We used another pericardial bioprosthesis in one case and a mechanical prosthesis in three. No mortality was noted for the patients with reoperations, all of which were elective.

There were only four patients with structural deterioration of the valve for an actuarial rate of $76 \%$ (CL $52 \%$ to $100 \%$ ) of patients free of structural valve failure at 10 years and a linearized rate of $0.5 \%$ patient-years (Fig. 3). The valve was considered as deteriorated when a mitral insufficiency of grade III or IV was observed or when the mean transvalvular gradient was above $8 \mathrm{~mm} \mathrm{Hg}$. Despite the short coaptation area of the leaflet, no major central insufficiency was noted in the patients who were being followed up. Except in patients with structural failure, we observed no major structural change. Four patients underwent reoperation, one after the end of the study. The structural change was stenosis without regurgitation caused by valve calcification in all cases. The explanted valve showed diffuse micromineralization of the three leaflets. It is notable that no leaflet tear was observed. Patient ages were 23, 27, 40, and 41 years, and the delay for calcification was $9,8.5,5.5$, and 5 years, respectively. No major structural change was noted in the other patients who were followed up, but echocardiographic studies were not performed in all patients.

\section{Age}

Forty-six patients were under 60 years of age. In this group, with a mean follow-up of 5.6 years and total follow-up of 258 patient-years, we observed two valve-related deaths and nine valve-related events (Table I). Actuarial survival was $81 \%(\mathrm{CL}$ $69 \%$ to $93 \%$ ) at 10 years. Actuarial freedom from 


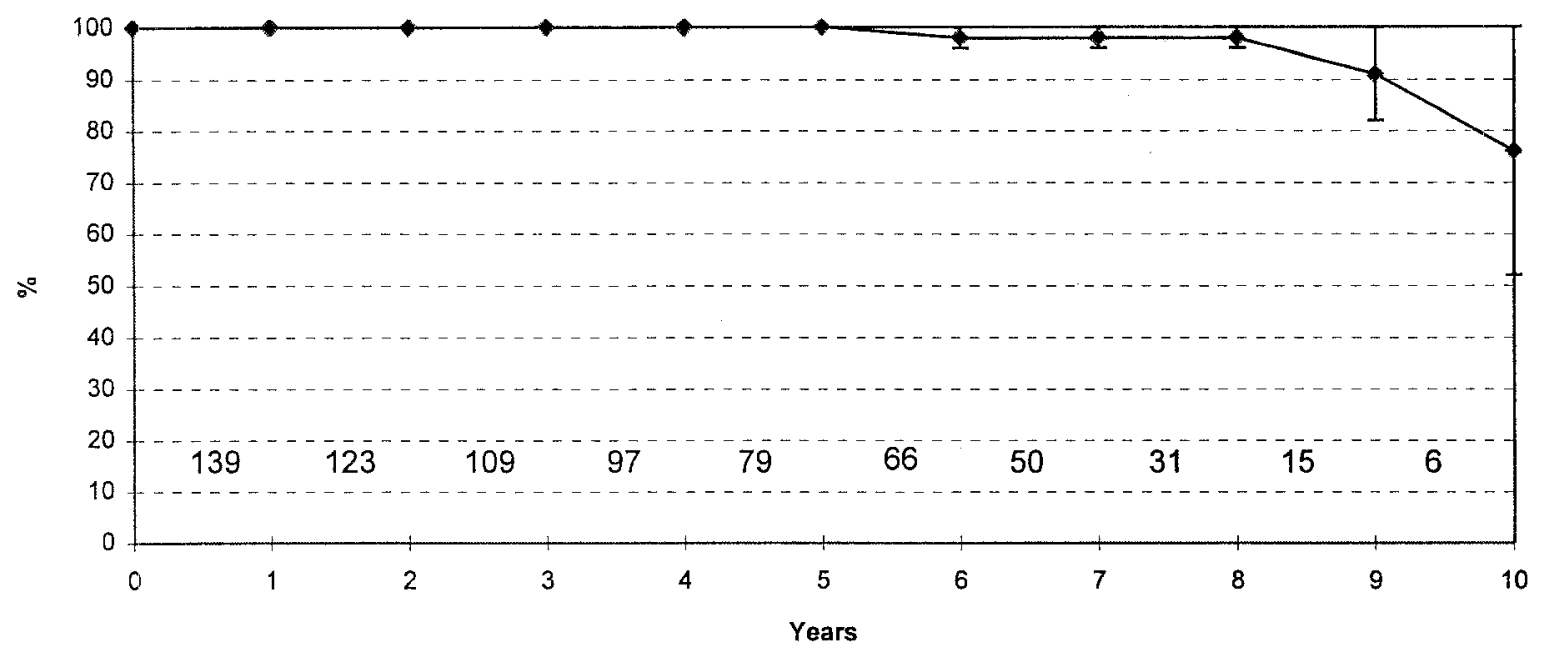

Fig. 3. Actuarial rates for freedom from structural deterioration.

Table I. Valve-related complications

\begin{tabular}{llll}
\hline & All patients & Patients $<60 y r$ & Patients $>60 y r$ \\
\hline Valve-related death & $0.8 \%(89 \%-99 \%)$ & $0.7 \%(90 \%-100 \%)$ & $0.8 \%(90 \%-98 \%)$ \\
Thromboembolism & $0.7 \%(90 \%-100 \%)$ & $0.3 \%(94 \%-100 \%)$ & $0.9 \%(90 \%-100 \%)$ \\
Endocarditis & $0.4 \%(94 \%-100 \%)$ & $0(100 \%)$ & $0.6 \%(92 \%-100 \%)$ \\
Structural failure & $0.5 \%(52 \%-100 \%)$ & $1.5 \%(12 \%-82 \%)$ & $0(100 \%)$ \\
Reoperations & $0.5 \%(82 \%-98 \%)$ & $1.1 \%(58 \%-98 \%)$ & $0.2 \%(96 \%-100 \%)$ \\
Anticoagulation-related hemorrhage & $1.2 \%(70 \%-98 \%)$ & $1.5 \%(52 \%-100 \%)$ & $1.1 \%(84 \%-100 \%)$ \\
All complications & $3.1 \%(46 \%-86 \%)$ & $4.2 \%(1 \%-71 \%)$ & $2.8 \%(70 \%-90 \%)$ \\
\hline
\end{tabular}

Valves are linearized rate and actuarial freedom (95\% CL).

valve-related death was $95 \%$ (CL $90 \%$ to $100 \%$ ), from endocarditis $100 \%$, from thromboembolism 97\% (CL $94 \%$ to $100 \%$ ), from deterioration $47 \%$ (CL $12 \%$ to $82 \%$ ), and from reoperation $78 \%$ (CL $58 \%$ to $98 \%$ ). Actuarial freedom of all valve-related complications was $36 \%$ (CL $1 \%$ to $71 \%$ ).

One hundred four patients were older than 60 years. In this group, with a mean follow-up of 4.3 years and a total follow-up of 452 patient-years, we observed four valve-related deaths and nine valve-related events (Table I). Actuarial survival was $65 \%$ (CL 52\% to $78 \%$ ) at 10 years. Actuarial freedom from valve-related death was $94 \%$ (CL $90 \%$ to $98 \%$ ), from endocarditis $96 \%$ (CL 92\% to 100\%), from thromboembolism 95\% (CL $90 \%$ to $100 \%$ ), from deterioration $100 \%$, and from reoperation $98 \%$ (CL 96\% to $100 \%$ ). Actuarial freedom of all valve-related mortality and morbidity was $80 \%$ (CL $70 \%$ to $90 \%$ ).

\section{Hemodynamics}

Among the 30 patients assessed by echocardiography at the time of follow-up in our institution, 14 had a mitral valve replacement with a $27 \mathrm{~mm}$ bioprosthesis, eight with a $29 \mathrm{~mm}$, six with a $31 \mathrm{~mm}$, and two with a $33 \mathrm{~mm}$. Hemodynamics data are shown in Table II.

\section{Discussion}

The procedure of choice for mitral valve disease is mitral repair ${ }^{5}$; it represents about $50 \%$ of our mitral surgery activity. The use of mitral homografts ${ }^{6}$ increases the indications for repair, but the problem of technical procedure and procurement introduces a major limitation. For other patients, the ideal valve is not yet available and surgeons need to choose between mechanical prostheses with the risk of anticoagulant-related hemorrhage and biologic valves with the risk of deterioration and reoperation. ${ }^{7}$ The use of biologic valves in the mitral position is controversial. The incidence of structural deterioration and the need for reoperation appear higher than in the aortic position, and many studies conclude with a clinical use limitation in patients over 70 years of age.

Pericardial bioprostheses have been clinically 
Table II. Hemodynamic data

\begin{tabular}{cccc}
\hline $\begin{array}{c}\text { Valve size } \\
(\mathrm{mm})\end{array}$ & $n$ & $\begin{array}{c}\text { Mean gradient } \\
(\mathrm{mm} \mathrm{Hg})\end{array}$ & $\begin{array}{c}\text { Effective orifice } \\
\left(\mathrm{cm}^{2}\right)\end{array}$ \\
\hline 27 & 14 & 4.1 & 2.6 \\
29 & 8 & 3.0 & 2.7 \\
31 & 6 & 3.0 & 2.6 \\
33 & 2 & 3.0 & 3.1 \\
\hline
\end{tabular}

used in human beings since 1970. The first generation of this type of valve has been withdrawn from the market because of its poor clinical results., ${ }^{8,9}$ The mode of deterioration was largely documented and was not due to pericardium failure but to design failure $^{10,11}$ or tissue preparation failure. ${ }^{12}$

The Carpentier-Edwards pericardial valve was designed with an original leaflet clamping technique which eliminates the retention suture and also abrasion risk. Pericardium is carefully procured and treated with glutaraldehyde. With these characteristics, this pericardial bioprosthesis showed satisfactory intermediate results ${ }^{13,14}$ in both positions, reestablishing pericardium as a good valve substitute. These results, especially in the mitral position, promise an interesting long-term follow-up.

Few reports are available with this type of pericardial valve, except for one publication with a long follow-up. ${ }^{15}$ The aortic and mitral Edwards pericardial valves were first used in Europe, and the aortic prosthesis received Food and Drug Administration (FDA) approval in 1991. The present models of the Carpentier-Edwards pericardial bioprostheses sold outside the United States are the model 2900 (aortic) and the model 6900 (mitral). The difference in these models as compared with the aortic model 2700 sold in the United States lies in the configuration of the valves' sewing rings. Considering that these changes to the sewing ring were not incorporated until after the initiation of the model 2700 U.S. clinical trials, Edwards CVS division of Baxter Healtcare Corporation made the business decision to continue its original study with the model 2700 rather than start over with a new submission to the FDA on the models 2900 and 6900 . The company is currently in the process of developing a mitral version for future sale within the United States.

We report here one of the largest studies with this prosthesis but with a low number of patients at risk at 10 years and a mean 4.7-year follow-up.

We have been using these pericardial valves in the mitral position since 1984 in a total of 149 patients, who represent more than half of all valve replace- ments during the same period. It is the only bioprosthesis used for mitral valve replacement in our institution. We used these pericardial valves in patients over 60 years of age and in case of contraindications to anticoagulant therapy. We also used it in patients with poor clinical status and in young patients who wish to avoid anticoagulant treatment after informed consent.

In this study, overall rate of survival was $71 \%$ and the rate and cause of death were similar to those in other reports on mitral valve replacement. ${ }^{16,17}$ There were six valve related-deaths, among them two sudden deaths. No postmortem examination was available when these deaths occurred in other institutions or at home. Despite this fact the actuarial freedom of valve-related death is comparable with other studies.

The morbidity with this prosthesis is low. The most important complication was embolism in five patients but without thrombosis of the prosthesis. This low rate of embolism occurred in the absence of anticoagulation in patients in sinus rhythm or with a low international normalized ratio $(1.5<$ INR $<2$ ) in patients in atrial fibrillation. Freedom of embolism at 10 years is $95 \%$. This rate appears lower than the rate obtained in patients with mechanical prostheses who were much younger in many studies. ${ }^{18}$

Despite the large number of patients with anticoagulation treatment because of atrial fibrillation only nine accidents and one death caused by anticoagulant-related hemorrhage were noted. The rate of hemorrhage (1.2\% patient-year) is lower than those published with mechanical prostheses. ${ }^{16,19}$ The greater risk with mechanical prosthesis is related to the higher recommended INR (INR > 2.5).

We observed only four cases of structural deterioration. Tissue deterioration was always the same: leaflet calcification leading to valve stenosis. Explanted valves showed intrinsic calcification of the three leaflets. No leaflet tears were observed in this study.

Comparison of the long-term results with other valves is difficult because many factors vary between cardiac surgical teams. Our results at 10 years in particular are better than those obtained with earlier pericardial bioprostheses. There is a significant difference in the structural deterioration rate between the Carpentier-Edwards and the first generation of pericardial valves (Ionescu-Shiley, Shiley, Inc, Calif.; Hancock, Medtronic, Cardiopulmonary Division, Anaheim, Calif.). The reported rates for the Io- 
nescu-Shiley ${ }^{20}$ are close to $40 \%$ at 10 years, whereas it is approximately $30 \%$ for the Hancock pericardial bioprosthesis $^{21}$ at 7 years.

The behavior of these pericardial valves compares well with those published for standard porcine valves. $^{22,23}$ The last generation of porcine valves showed promising results, ${ }^{24,25}$ but no comparison is available between these porcine valves and the latest generation of pericardial valves. This type of study is needed especially for patients younger than 70 years of age.

A comparison between mechanical and biologic valves was made by Bloomfield ${ }^{26}$ and Hammermeister. ${ }^{27}$ This study was carried out on the first generation of pericardial valves and porcine valves. The better results obtained with the latest generation of pericardial valves will certainly change the results of the comparison. However, Cohn and colleagues ${ }^{28}$ believe long-term survival after mitral valve replacement is primarily related to patient variables.

As already reported, ${ }^{29}$ the influence of age is again clearly shown in this study. No patient over 50 years of age had structural deterioration at a mean follow-up period of 4.7 years. This pericardial valve appears to be a reliable choice for patients over 50 years and is a prosthesis of choice in patients over 60 years even in case of atrial fibrillation. We think that selection of patients remains indispensable even with the latest generation of biologic valves and that a more durable bioprosthesis in the mitral position for young patients is needed.

\section{Conclusion}

With a low rate of valve-related events at 10 years and especially a low incidence of structural failure, this prosthesis reestablishes the pericardium as a valve substitute in the mitral position. It is a reliable choice in patients over 60 years. However, because of the history of bioprostheses and our relatively short mean follow-up of 4.7 years, further studies and longer follow-up are necessary to provide definitive conclusions.

\section{REFERENCES}

1. Frater RW, Salomon NW, Rainer WG, Cosgrove DM, Wickman E. The Carpentier-Edwards pericardial valve: intermediate results. Ann Thorac Surg 1992;53:764-71.

2. Perier P, Mihaileanu S, Fabiani JN, Deloche A, Chauvaud S, Jindani A, Carpentier A. Long-term evaluation of the Carpentier-Edwards pericardial valve in the aortic position. J Cardiac Surg 1991;6:589-94.

3. Aupart M, Neville P, Meurisse Y, Dreyfus X, Sirinelli A, Marchand M. The Carpentier-Edwards pericardial mitral bioprosthesis: intermediate follow up in 121 patients. In: Gabbay S, Frater R, editors. New horizon and the future of heart valve bioprostheses. Proceeding of the third meeting of the international association for cardiac biological implants. Austin, TX: Silent partners, 1994:123-34.

4. Edmunds LH Jr, Clark RE, Cohn LH, Miller DC, Weisel RD. Guidelines for reporting morbidity and mortality after cardiac valvular operations. Ann Thorac Surg 1988;46: 257-9

5. Deloche A, Jebara VA, Relland JY, et al. Valve repair with Carpentier techniques: the second decade. J Thorac Cardiovasc Surg 1990;99:990-1002.

6. Acar C, Farge A, Ramsheyi A, et al. Mitral valve replacement using a cryopreserved mitral homograft. Ann Thorac Surg 1994:57:746-8.

7. Bloomfield P, Wheatley DJ, Prescott RJ, Miller HC. Twelve year comparison of a Bjork-Shiley mechanical valve with porcine bioprosthesis. N Engl J Med 1991;324:573-9.

8. Gallo I, Nistal F, Revuelta JM, Garcia-Statue E, Artinano E, Duran CG. Incidence of primary valve failure with the Ionescu-Shiley pericardial valve. J Thorac Cardiovasc Surg 1985;90:278-80.

9. Bortolotti U, Milano A, Guerra F, Mazzucco A, Mossuto E, Thiene $\mathrm{G}$, et al. Failure of Hancock pericardial xenografts: Is prophylactic bioprosthetic replacement justified? Ann Thorac Surg 1991;51:430-7.

10. Walley VM, Keon WJ. Patterns of failure in Ionescu-Shiley bovine pericardial valves. J Thorac Cardiovasc Surg 1987;93: 925-33.

11. Walley VM, Rubens FD, Campagna M, Pipe AL, Keon WJ. Patterns of failure in Hancock pericardial bioprostheses. J Thorac Cardiovase Surg 1991;102:187-94.

12. Leandri J, Bertrand P, Mazzucotelli JP, Loisance D. Mode of failure of the Mitroflow pericardial valve. J Heart Valve Dis 1992;1:225-31.

13. Aupart M, Neville P, Dreyfus X, Meurisse Y, Sirinelli A, Marchand $M$. The Carpentier Edwards pericardial aortic valve: intermediate results in 420 patients. Eur $\mathrm{J}$ Cardio Thorac Surg 1994;8:277-80.

14. Meyns B, Szecsi J, Flameng W, Daenen W. Aortic and mitral valve replacement with the Carpentier-Edwards pericardial bioprosthesis: mid-term clinical results. J Heart Valv Dis 1993;2:66-70.

15. Conrad Pelletier L, Carrier M, Leclerc Y, Dyrda I. The Carpentier Edwards pericardial bioprosthesis: clinical experience with 600 patients. Ann Thorac Surg;60:S297-302.

16. Fernandez J, Laub GW, Adkins MS, et al. Early and late results after valve replacement with the St. Jude Medical prosthesis in 1200 patients. J Thorac Cardiovasc Surg 1994; 107:394-407.

17. Magilligan DJ, Lewis JW, Tilley B, Peterson E. The porcine bioprosthetic valve: twelve years later. J Thorac Cardiovasc Surg 1985;89:499-507.

18. Hauge Nitter S, Abdelnoor M. Ten year experience with the Medtronic Hall valvular prosthesis. Circulation 1989; 80(suppl I):I-43-8.

19. Czer LSC, Chaux A, Matloff JM, et al. Ten year experience with the St. Jude Medical valve for primary valve replacement. J Thorac Cardiovasc Surg 1990;100:44-5.

20. Masters RG, Pipe AL, Bedart JP, et al. Long term clinical results with the Ionescu-Shiley pericardial xenograft. J Thorac Cardiovasc Surg 1991;101:81-9. 
21. Bortolotti U, Milano A, Guerra F, et al. Failure of Hancock pericardial xenografts: Is prophylactic bioprosthetic replacement justified? Ann Thorac Surg 1991;51:430-7.

22. Burdon TA, Miller DC, Oyer PE, et al. Durability of porcine valve at fifteen years in a representative North American patient population. J Thorac Cardiovasc Surg 1992;103:238-52.

23. Jamieson WRE, Allen P, Miyagishima RT, et al. The Carpentier Edwards Standard porcine bioprosthesis. J Thorac Cardiovasc Surg 1990;99:543-61.

24. Barratt-Boyes BG, Jaffe WM, Hong Ko P, Whitlock RML. The zero pressure fixed Medtronic Intact porcine valve: an 8.5 year review. J Heart Valv Dis 1993;2:604-11.

25. Myken SU, Caidahl K, Larsson S, Berggren H. 10 year experience with the Biocor porcine bioprosthesis in the mitral position. J Heart Valy Dis 1995;4:63-69.

26. Bloomfield P, Wheatley DJ, Prescott RJ, Miller HC. Twelve year comparison of a Bjork-Shiley mechanical valve with porcine bioprosthesis. N Engl J Med 1991;324:573-9.

27. Hammermeister KE, Sethi GK, Henderson WG, et al. A comparison of outcomes in men 11 years after heart valve replacement with a mechanical valve or bioprosthesis. $\mathrm{N}$ Engl J Med 1993;328:1289-95.

28. Cohn LH, Allred EN, Cohn LA, et al. Early and late risk of mitral replacement. J Thorac Cardiovase Surg 1985;90:872-81.

29. Jamieson WRE, Rosado LJ, Munro AI, et al. Carpentier Edwards standard porcine bioprosthesis: primary tissue failure by age group. Ann Thorac Surg 1988;46:155-62.

\section{Availability of Journal back issues}

As a service to our subscribers, copies of back issues of The Journal of Thoracic and Cardiovascular Surgery for the preceding 5 years are maintained and are available for purchase from Mosby at a cost of $\$ 15.00$ per issue until inventory is depleted. The following quantity discounts are available: $25 \%$ off on quantities of 12 to 23 , and one third off on quantities of 24 or more. Please write to Mosby-Year Book, Inc., Subscription Services, 11830 Westline Industrial Drive, St. Louis MO 63146-3318, or call 800-453-4351 or 314-453-4351 for information on availability of particular issues. If unavailable from the publisher, photocopies of complete issues may be purchased from UMI, 300 N. Zeeb Rd., Ann Arbor, MI 48106, 313-761-4700. 